Article

\title{
Use of the WRF-DA 3D-Var Data Assimilation System to Obtain Wind Speed Estimates in Regular Grids from Measurements at Wind Farms in Uruguay
}

\author{
Gabriel Cazes Boezio ${ }^{1, *}$ and Sofía Ortelli ${ }^{1,2}$ \\ 1 School of Engineeering, Universidad de la República, Montevideo 11300, Uruguay; sofiao@fing.edu.uy \\ 2 Usinas y Trasmisiones del Estado (UTE), Montevideo 11200, Uruguay \\ * Correspondence: agcm@fing.edu.uy; Tel.: +598-27115279
}

Received: 31 August 2019; Accepted: 24 October 2019; Published: 29 October 2019

\begin{abstract}
This work assessed the quality of wind speed estimates in Uruguay. These estimates were obtained using the Weather Research and Forecast Model Data Assimilation System (WRF-DA) to assimilate wind speed measurements from $100 \mathrm{~m}$ above the ground at two wind farms. The quality of the estimates was assessed with an anemometric station placed between the wind farms. The wind speed estimates showed low systematic errors at heights of 87 and $36 \mathrm{~m}$ above the ground. At both levels, the standard deviation of the total errors was approximately $25 \%$ of the mean observed speed. These results suggested that the estimates obtained could be of sufficient quality to be useful in various applications. The assimilation process proved to be effective, spreading the observational gain obtained at the wind farms to lower elevations than those at which the assimilated measurements were taken. The smooth topography of Uruguay might have contributed to the relatively good quality of the obtained wind estimates, although the data of only two stations were assimilated, and the resolution of the regional atmospheric simulations employed was relatively low.
\end{abstract}

Keywords: data assimilation; 3D-Var

\section{Summary}

This work evaluated the use of techniques for assimilation of data from field measurements into initial conditions of atmospheric numerical simulations in order to obtain wind estimates in Uruguay, at heights of $100 \mathrm{~m}$ above the ground and lower. The wind was estimated with hourly frequency in a regular grid that covers the country. The field data to be assimilated was operatively measured in wind farms installed in Uruguay, using anemometers placed $100 \mathrm{~m}$ above the ground. The data was assimilated into initial conditions for the Weather Research and Forecast regional model (WRF) of the National Center of Atmospheric Research (NCAR), [1] using the module for data assimilation included in this model, the WRF-DA module [2].

The data assimilation process, also called analysis, is an essential component of numerical atmospheric forecasts, and its main purpose is to generate initial conditions for the predictions. The variables that compose an initial condition are called prognostic variables because the model uses their values at a given instant to compute their values at a later time. To generate an initial condition for a specific numerical model at a given time, a first approximation is generally used. This first approximation, called "background condition", usually consists of a prediction for the same instant, obtained with the same model, from previous initial conditions. The data assimilation system must combine the information from the background condition with the information from measurements of atmospheric variables (or variables of systems related to it; for example, the ocean, the soil, or the cryosphere). This combination of information is done in a way that optimizes the quality of the result in 
statistical terms, either minimizing the expected value of the sum of its quadratic errors or maximizing its likelihood. Note that the short-term predictions used as background values are, in turn, affected by field measurements that were assimilated during previous times. This allows considering information from regions or atmospheric levels in which few measurements are available since measurements, done earlier in other regions or at other levels, can propagate their influence through atmospheric dynamical processes into the zones that have relatively fewer observations.

Kalnay [3] described the main techniques for data assimilation that are currently used, such as optimal interpolation, 3D-Var, Kalman filters, ensemble Kalman filters, and 4D-Var. The WRF-DA system implements the 3D-Var [4] and 4D-Var techniques [5], and a technique that combines the ensemble Kalman filter with 3D-Var [6,7]. Harlim [8] pointed that the referred techniques assume that the errors from the background conditions and the field measurements are unbiased and normally distributed, although numerical models inevitably have systematic errors. These assumptions can provide reasonable estimates of the first-order statistics while being practical to implement. However, these methodologies require caution for interpreting their higher-order statistical estimates, and an important challenge in data assimilation is to use existing methods in the presence of model systematic errors. The author proposed methodologies to mitigate the effects of model systematic errors on the results of the assimilation process. Rao and Sandu [9] proposed an a-posteriori error estimation methodology that quantifies the impact of model and data errors on the inference results of inverse problems, including the 4D-Var assimilation process. The model and data errors considered include both unbiased noise and systematic biases. The authors found that the proposed methodology could be useful to reduce and quantify uncertainties in a real-time system with feedback. Besides, the error estimates can be used to locate faulty sensors and to determine areas of maximum sensitivity, where improvements in the stations network or an increase in model resolution may be required.

In addition to its direct use in the numerical prediction process, the results of data assimilation can be considered "pseudo-observations" of atmospheric variables in regular grids. Note that these do not consist purely of interpolations of field measurements in a regular grid since they also consider the information from short-term predictions. The uses of the pseudo-observations obtained from a data assimilation process can be very broad, but they require an evaluation of their quality by comparison with field measurements not used in the assimilation process.

The current work used the rather conventional 3D-Var assimilation technique. In Section 2, we described the data used, both from field measurements and from numerical predictions used as background conditions, and we referred to the quality control method used for the field data from the wind farms. In Section 3, we described the main aspects of the 3D-Var assimilation technique and its implementation in this work using the WRF DA system. In Section 4, we described the main results, and in Section 5, we presented the conclusions.

\section{Data Description}

The wind data used in the data assimilation process was obtained from two anemometers installed in the "Rosendo Mendoza" (WF1) and "Valentines" (WF2) wind farms. The geographic locations of these wind farms are shown in Figure 1. The anemometers were placed $100 \mathrm{~m}$ above the ground, and they recorded mean velocities for successive periods of $15 \mathrm{~min}$, which were transmitted to the National Dispatch of Electric Charges of Uruguay, operated by the Electricity Market Administration (Administración del Mercado Eléctrico; ADME) and the National Administration of Electric Power Plants and Transmissions (Usinas y Trasmisiones del Estado; UTE), and Uruguayan National Public Electricity Utility Organizations. In addition to the wind measurements, the mean electric power generated in the same 15-min periods and the corresponding quantity of aerogenerators that were effectively active were also transmitted by each wind farm. These additional data allowed for a quality control analysis of the measurements, as described by Orteli and Cazes Boezio [10]. With the historical information of wind velocity and electric power generated, the authors built an empirical wind-power curve for each wind farm. In those cases in which not all the aerogenerators of the wind farm were 
active, the power generation that would correspond to a condition of full availability was estimated by linear extrapolation. The authors considered that those combinations of wind and generated power that depart from the empirical curve beyond certain thresholds were suspicious of being affected by malfunctioning of the measurement or recording systems, or by occasional interference of the wake of an aerogenerator with the anemometer. The data from WF1 and WF2 available for this study were from the months from January to May and from November to December of 2017 (seven months).

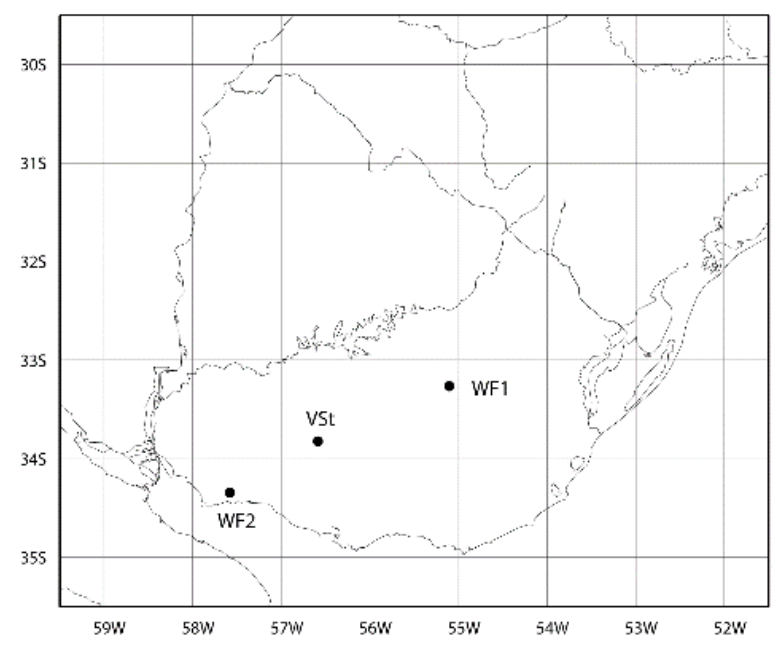

Figure 1. The geographic location of anemometers used for data assimilation (WF1 and WF2) and validation (Vst).

To evaluate the quality of the pseudo-observations obtained through the implemented data assimilation process, an independent station was used ("validation station", VSt), which is located at Colonia Arias, Uruguay. The station location is also shown in Figure 1. The station measures wind speed and direction at heights of 87 and $36 \mathrm{~m}$ above the ground and is part of a network of stations that measures wind velocity and solar radiation that has been operated by UTE since 2009. This network is described by Cornalino and Draper [11], and its measurements (that include wind velocities averaged every $10 \mathrm{~min}$ ) are made available online by UTE. In recent years, many of the anemometric stations operated by UTE have become affected by wind farms. The VSt of Colonia Arias has been active since 2011, and during the period studied in this work, it was not affected by any wind farm. Figure 2 shows the wind speed at the WF1, WF2, and Vst sensors averaged for each local hour during the seven months considered.

The assimilation process uses regional simulations computed with the WRF model from NCAR, as shown by Cazes Boezio and Orteli [12]. The regional simulations take their initial and boundary conditions from global predictions made by the Global Forecast System (GFS) of the National Ocean and Atmosphere Administration (NOAA) of the Unites States. The horizontal grid of the regional simulations has a resolution of $30 \mathrm{~km}$ in the zonal and meridional directions, as shown in Figure 3 . The vertical direction is discretized in 54 levels, 7 of which are within the first $100 \mathrm{~m}$ of height above the ground. In Appendix A, we indicated the parameterizations of physical processes employed, and we defined in detail the vertical discretization. The regional simulations have two purposes: first, they generate the background conditions into which the data measured in WF1 and WF2 are assimilated; and second, they allow for the estimation of the matrix of covariances of the errors of these background conditions. In Section 3, the hours of initialization and the simulated periods used for each one of these purposes were specified. 

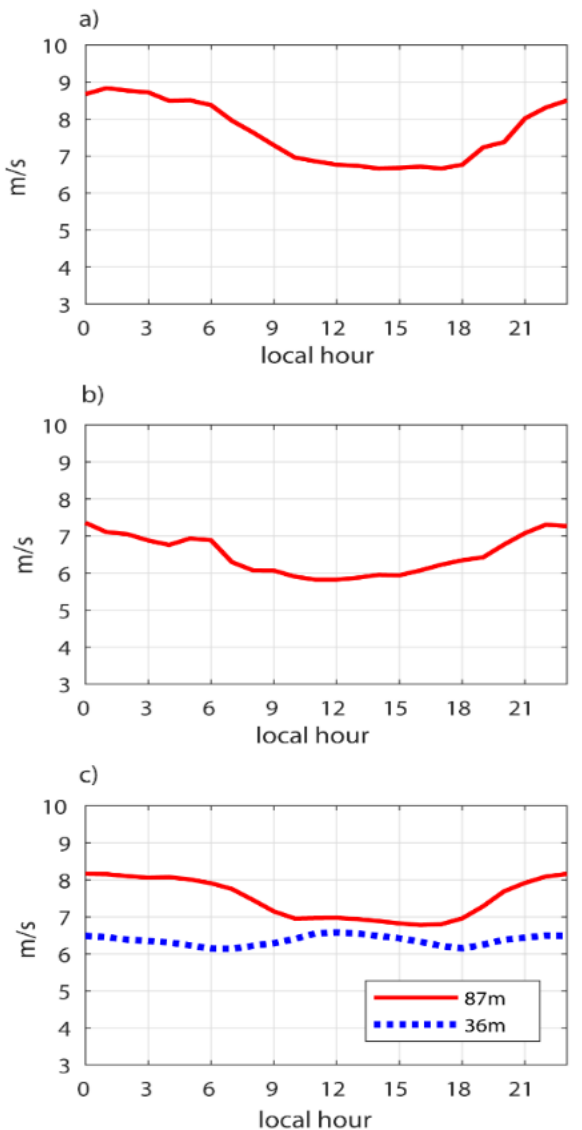

Figure 2. Mean wind velocity, as a function of the local hour, for the WF1 (a), WF2 (b), and VSt stations (c). At the VSt station, the solid line shows the mean velocity for the anemometer $87 \mathrm{~m}$ above the ground, and the dotted line shows the anemometer $36 \mathrm{~m}$ above the ground.

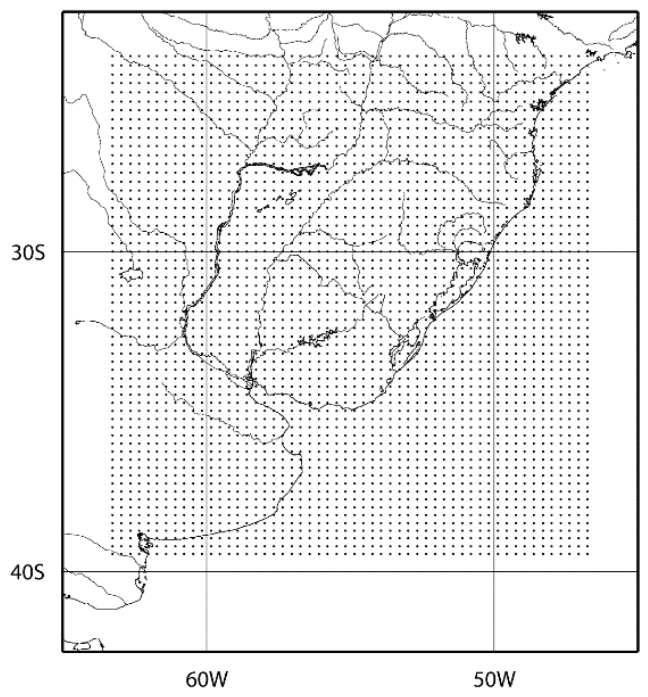

Figure 3. Grid points of the horizontal discretization used in the regional simulations.

\section{Methods}

Next, we described the main aspects of the 3D-Var assimilation technique, which was used in this work and is available in the WRF-DA system. A complete description of this technique and its implementation in the WRF-DA system can be found in the NCAR Technical Note 453 [13], in 
Barker et al. [4] and Barker et al. [2], while the corresponding operational details are given in the WRF-DA User Guide [14].

The background condition information is displayed as a vector called $\mathbf{x}_{\mathbf{b}}$, which contains the values of all the different prognostic variables that compose the background condition in a certain conventional order. This information is displayed for each variable and each point of the grid. The field measurements that are to be assimilated, obtained at the same instant that corresponds to $\mathbf{x}_{\mathbf{b}}$, are displayed as a vector called $\mathbf{y}$, also in a conventional order. The initial condition determined by the assimilation system is expressed as a vector called $\mathbf{x}_{\mathbf{a}}$, with a structure analogous to that of $\mathbf{x}_{\mathbf{b}} \cdot \mathbf{x}_{\mathbf{a}}$ combines the information from the background condition $\mathbf{x}_{\mathbf{b}}$ and the field measurements contained in $\mathbf{y}$, as expressed in Section 1. The 3D-Var technique determines the vector $\mathbf{x}_{\mathbf{a}}$ as that of maximum likelihood, conditioned to the information of the background condition and the field measurements, and is the vector $\mathbf{x}$ that minimizes the following expression [3]:

$$
J(x)=\frac{1}{2}\left(x-x_{b}\right)^{T} B^{-1}\left(x-x_{b}\right)+\frac{1}{2}(y-H(x))^{T} R^{-1}(y-H(x))
$$

that is, $J\left(x_{a}\right)$ must be minim. In this formula, $\mathbf{B}$ and $\mathbf{R}$ are the matrices of error covariances of the background condition $\mathbf{x}_{\mathbf{b}}$ and the field measurements $\mathbf{y}$, respectively. It is assumed that these errors are normal variables and are unbiased. The $\mathbf{B}$ matrix is thus related to the accidental errors of $\mathbf{x}_{\mathbf{b}}$, while the model systematic errors or biases are assumed to be zero, as pointed out in [8]. Matrix $\mathbf{B}$ is defined as follows:

$$
B \equiv E\left(\left(x_{b}-x_{t}\right) \cdot\left(x_{b}-x_{t}\right)^{T}\right)
$$

where $\mathbf{E}$ represents the expected value of the elements of the matrix $\left(x_{b}-x_{t}\right) \cdot\left(x_{b}-x_{t}\right)^{T}$, and $\mathbf{x}_{\mathbf{t}}$ is the vector of the true values of the variables contained in $\mathbf{x}_{\mathbf{b}}$. Note the actual values of $\mathbf{x}_{\mathbf{t}}$ are unknown, so it becomes necessary to define a technique to estimate the values of $\mathbf{B}$ from available information.

$\mathbf{H}(\mathbf{x})$ is an operator that yields results analogous to the variables $\mathbf{y}$ from the model prognostic variables included in $\mathbf{x}$. As an example, if an element of $\mathbf{y}$ represents the measurement of the meridional wind at a certain geographical location and a certain height, $\mathbf{H}(\mathbf{x})$ interpolates the values of the meridional wind field obtained from the numerical model at the geographical location and the height of this measurement. The H operator is generally non-linear, but it is possible to linearize it with the following approximation:

$$
H(x)=H\left(x_{b}+x-x_{b}\right) \approx H(x)+\nabla H\left(x-x_{b}\right),
$$

where $\mathbf{\nabla H}$ is the gradient of $\mathbf{H}(\mathbf{x})$. If the linearized expression for $\mathbf{H}(\mathbf{x})$ is used, $\mathbf{J}(\mathbf{x})$ assumes a quadratic form.

It is assumed that the errors of the field measurements contained in vector $\mathbf{y}$ are statistically independent of each other, so $\mathbf{R}$ is a diagonal matrix; its diagonal contains the variances of the errors of each field measurement.

The matrix $\mathbf{B}$ is essential to this assimilation system. First, its non-diagonal terms contain the covariances of $\mathbf{x}_{\mathbf{b}}$ errors at different grid points and also the covariances of errors of different variables. These covariances are necessary to propagate the information related to any field measurement through the horizontal and vertical directions and allow measurement of a specific variable to affect the analysis of others. In addition to this, the matrices $\mathbf{B}^{\mathbf{1}}$ and $\mathbf{R}^{\mathbf{- 1}}$ together determine the relative importance of the background conditions $\mathbf{x}_{\mathbf{b}}$ and the field measurements $\mathbf{y}$ to determine the analysis $\mathbf{x}_{\mathbf{a}}$.

The WRF-DA system offers two methods to estimate B: the National Meteorological Center method (NMC), described by Parrish and Derber [15], and a method based on ensembles of predictions ([1], Chapter 9). Due to the availability of computer resources, we used the NMC method, which is relatively more economic. This method requires a database of pairs of $\mathbf{x}_{\mathbf{b}}$; each pair has two short-term predictions for the same hour obtained with different forecast horizons (for example, 12 and $24 \mathrm{~h}$ ), and consequently with different initial conditions. The pairs of predictions correspond to certain hours of 
the day (for example, 0:00 and 12:00 GMT), and cover a certain period (for example, one year). It is assumed that the differences between the forecasts of each pair have statistical properties analogous to those of the background condition errors, and in particular, to estimate $B$, the following approximation can be used:

$$
B=E\left(\left(x_{b}-x_{t}\right)^{T} \cdot\left(x_{b}-x_{t}\right)\right) \approx E\left(\left(x_{b}^{12 h s}-x_{b}^{24 h s}\right)^{T} \cdot\left(x_{b}^{12 h s}-x_{b}^{24 h s}\right)\right)
$$

where $x_{b}^{12 h s}$ and $x_{b}^{24 h s}$ are a generic pair of predictions with 12 and $24 \mathrm{~h}$ time horizons, respectively. The validation of this technique to estimate $\mathbf{B}$ is empirical.

Note that, if $\mathbf{n}$ is the length of the $\mathbf{x}_{\mathbf{a}}$, and $\mathbf{x}_{\mathbf{b}}$ vectors, the size of $\mathbf{B}$ is $\mathbf{n x n}$. This implies a matrix of very large dimensions that would cause important technical difficulties to operate with $\mathbf{B}$ or $\mathbf{B}^{\mathbf{- 1}}$, and even to store them in the computer memory. The 3D-Var technique implemented in the WRF-DA system solves this problem by factoring $\mathbf{B}$ as a product of certain matrices that have clear physical interpretations, allowing certain assumptions about their structures to be made and making them computationally tractable [2,4].

As a final remark in this subsection, we noted that both for the simulations of the background conditions and the estimation of the $\mathbf{B}$ matrix, a specific configuration of the WRF model was used, which here is the one described in Section 2.

\section{WRF-DA Implementation for This Work}

To apply the NMC method to estimate the matrix B, we used WRF-GFS simulations extended for $24 \mathrm{~h}$ and initialized at 0:00 GMT and 12:00 GMT during the entire year of 2016. The results obtained for 12 and $24 \mathrm{~h}$ after the initial conditions were used to estimate the matrix $\mathbf{B}$, as indicated in the previous section. In order to gain insight into the spatial structure of the covariances contained in $\mathbf{B}$, Decombes et al., [16] and Rivi [17] proposed "pseudo-single observation tests". Such tests consist of choosing a particular variable of $\mathbf{x}_{\mathbf{b}}$ in a particular grid point and suppose a hypothetical observation that increments in a fixed amount the background value of this variable at the selected grid point. The data assimilation process is carried on considering this single pseudo observation and prescribing a hypothetical value of the standard deviation of its error. Rivi [17] showed that the $\mathbf{x}_{\mathbf{a}}-\mathbf{x}_{\mathbf{b}}$ difference was proportional to the covariance between the errors of the background variable in question at the chosen grid point and the errors of the rest of the background variables at all the grid points. The plots of the $\mathbf{x}_{\mathbf{a}}-\mathbf{x}_{\mathbf{b}}$ differences for selected variables illustrate how the $\mathbf{B}$ matrix spreads the information of field measurements. In Appendix B, we summarized the fundamentals of the pseudo observation tests, and we showed some selected results for the $\mathbf{B}$ matrix estimated here.

The background conditions $\mathbf{x}_{\mathbf{b}}$ were obtained from WRF-GFS simulations initiated at 0:00, 6:00, 12:00, and 18:00 GMT, during those months of 2017 for which information from the WF1 and WF2 stations was available. We used the hourly results of these simulations from 4 to $9 \mathrm{~h}$ since the initialization of each simulation. In this way, four consecutive simulations could cover the $24 \mathrm{~h}$ of each day. The selected forecast horizon was the earliest for which the GFS prediction results were available in real-time, with some time left to carry out the processes described in this work. In this way, it is possible to implement these processes in an operative mode. For each local hour in Uruguay, Table 1 shows which WRF-GFS initialization cycle was used, and which hour within its forecast horizon corresponded to the background condition for that local hour. 
Table 1. Hours within the WRF simulations used to define the background conditions as a function of the initialization cycle and local time in Uruguay. Each row corresponds to an initialization cycle, and each column corresponds to a local hour in Uruguay. The hours used within each cycle are indicated, considering the hours elapsed since its initialization.

\begin{tabular}{|c|c|c|c|c|c|c|c|c|c|c|c|c|c|c|c|c|c|c|c|c|c|c|c|c|}
\hline \multirow[b]{2}{*}{$\begin{array}{c}\text { Initialization } \\
\text { Cycle }\end{array}$} & \multicolumn{24}{|c|}{ Local UY Hour } \\
\hline & $0^{*}$ & 1 & 2 & 3 & 4 & 5 & 6 & 7 & 8 & 9 & 10 & 11 & 12 & 13 & 14 & 15 & 16 & 17 & 18 & 19 & 20 & 21 & 22 & 23 \\
\hline $0: 00$ & & 4 & 5 & 6 & 7 & 8 & 9 & & & & & & & & & & & & & & & & & \\
\hline $6: 00$ & & & & & & & & 4 & 5 & 6 & 7 & 8 & 9 & & & & & & & & & & & \\
\hline $12: 00$ & & & & & & & & & & & & & & 4 & 5 & 6 & 7 & 8 & 9 & & & & & \\
\hline $18: 00$ & 9* & & & & & & & & & & & & & & & & & & & 4 & 5 & 6 & 7 & 8 \\
\hline
\end{tabular}

In the present study, the assimilation made for each hour was independent of the previous assimilations; the corresponding background condition only incorporated information from the GFS global simulation. This is called a "cold start". Alternatively, the background conditions could also have considered the field measurements made in previous hours. This alternative is called a warm start. The warm start method was tested in the context of the present work and obtained results of equivalent quality to those obtained with the cold start, so here we showed only the latter results. The similarity of the results from both methods might be because the assimilated information was very local; the assimilation of data in a wider region could influence the simulations in the area of interest over more hours and thus increase the relevance of assimilation from previous hours. The verification of this hypothesis requires a database of field measurements more complete than the one that was available for this work.

Each field measurement is specified to the WRF-DA system in a file that contains the day and time of the measurement, the geographic coordinates, and ground elevation of the corresponding station, the height of the measurement sensor, and the records of wind speed and direction. This information is used to generate the vector of field observations, y. Considering that the topography of the regional model has some degree of smoothing, the elevation of the specified terrain is not the actual elevation, but the elevation corresponding to the topography of the model interpolated to the station's location coordinates. The height specified for the sensors is the elevation of the station plus $100 \mathrm{~m}$. The specified module of wind speed is the average of the anemometer record for two consecutive 15-min periods centered on the hour for which the assimilation will be performed.

The specified wind direction is deduced from the background condition, interpolating each component of the wind vector to the geographical position and elevation of the anemometer. Although vanes are available at the stations, it was found that using their records produces results that are not as satisfactory as those obtained by deducing the wind direction from the background condition. This suggests that the quality of data obtained from these weathervanes is relatively poor, while regional short-term predictions are reasonably good with regard to this variable. It may be of interest to evaluate the effect of the assimilation of atmospheric pressure measurements on the wind direction obtained in the analysis, but no such observations were available to complete this analysis.

In addition, to estimate the $\mathbf{R}$ matrix, the WRF-DA system uses a file that specifies the standard deviations of the errors of the different kinds of field observations (obserr.txt). In the present work, we adjusted the errors specified in this file, proposing a value of $0.1 \mathrm{~m} / \mathrm{s}$ for wind speed, which is reasonable for the type of sensors installed in the stations considered here [18]. For wind direction, we kept the default value proposed in the obserr.txt file, $5^{\circ}$. We also pointed out that the WRF-DA system uses two "namelist" files to prescribe parameters to be set for the $\mathbf{B}$ matrix estimation and the computation of the resultant analysis ( $\mathbf{x}_{\mathbf{a}}$ vector). In this work, we used the default values for these parameters, which are indicated in the WRF-DA user guide [14]. 


\section{Results}

To evaluate the quality of the obtained pseudo-observations, we interpolated each component of the wind vector to the geographic location of VSt and the levels of 87 and $36 \mathrm{~m}$ above the ground, and then we computed the wind speed at these levels. Figure 4 a shows the systematic error or bias of the two levels for each hour of the day. The bias is defined as the average of the wind estimate at a given level and hour minus the corresponding observed value over all the studied days:

$$
b \equiv \overline{s_{a}}-\overline{s_{o b s}}
$$

where $s_{a}$ is the wind speed interpolated from the analysis to the location and level of each Vst sensor, and $s_{o b s}$ is the correspondent measured wind speed. The overline represents the average over all the studied days. Figure $4 \mathrm{~b}$ shows the relative bias, defined as the bias divided by the observed mean wind speed at the corresponding hour:

$$
b_{r e l} \equiv \frac{\overline{s_{a}}-\overline{s_{o b s}}}{\overline{s_{o b s}}}
$$

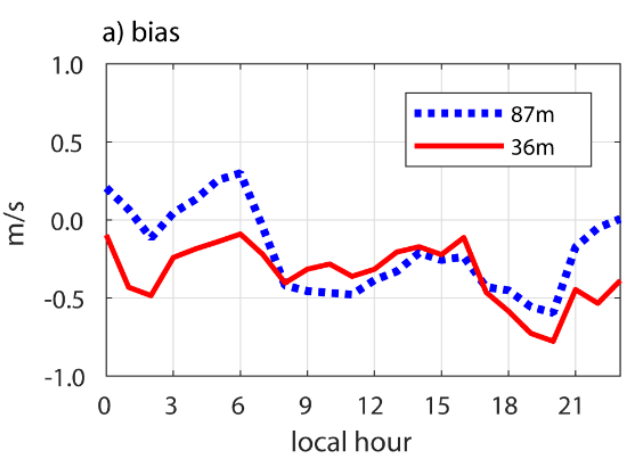

b) relative bias

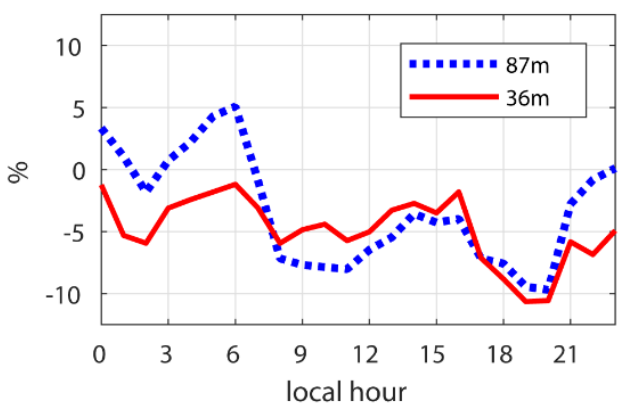

Figure 4. (a) Bias and (b) relative bias of wind estimates, which are $87 \mathrm{~m}$ above ground (red solid line) and $36 \mathrm{~m}$ above ground (blue dotted line), at VSt as a function of the local hour.

At $87 \mathrm{~m}$, the bias was moderate, generally smaller than $0.5 \mathrm{~m} / \mathrm{s}$, while relative bias was generally smaller than 5\%. At $36 \mathrm{~m}$, the bias and the relative bias were similarly moderate: the bias was generally smaller than $0.5 \mathrm{~m} / \mathrm{s}$, while the relative bias during some hours was slightly larger than that found at $87 \mathrm{~m}$. Note that $87 \mathrm{~m}$ above the ground was similar to the elevation of the assimilated observations, while the 36-m elevation was significantly closer to the ground. The moderate systematic errors found at both elevations indicated that the data assimilation technique effectively combined the information from short-term WRF predictions and wind measurements. The wind measurements from the wind farms lacked information about elevations relatively close to the ground, e.g., at $36 \mathrm{~m}$, while the WRF simulations did include this information since they considered several elevations within the first $100 \mathrm{~m}$ above the ground but had errors of their own. The assimilation process corrected these errors at the locations and elevations of the anemometers in the wind farms and also transmitted the effects of 
these gains to other regions and elevations. The information that allowed these gains to spread was contained in the background error matrix B. To further illustrate this point, Figure 5 shows the bias of the background conditions $36 \mathrm{~m}$ above the ground at VSt and the bias resulting from the assimilation process (also included in Figure 4a). The background bias was larger for all hours. Since both biases were means of errors, it was possible to compute the significance of their difference with a two-tailed Student t-test [19]. It was found that these biases were different with a significance value lower than 0.05 for the local hours from 0:00 to 16:00, and from 21:00 to 23:00 (the hours with significant differences are indicated with a green bar in Figure 5).

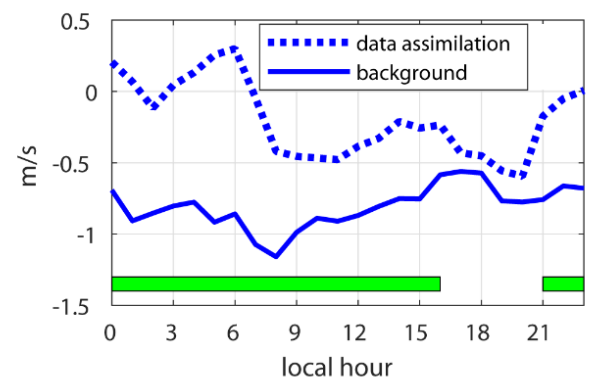

Figure 5. The bias of two wind estimates $36 \mathrm{~m}$ above ground at VSt, as a function of the local hour. The solid line indicates the wind estimates from the background conditions, and the dotted line indicates the wind estimates from the assimilation process. The green bar indicates the hours for which the difference between both biases was significant at the $5 \%$ level, computed as indicated in the text.

Next, we presented two statistical parameters related to accidental errors. Figure 6 shows the Pearson correlation of estimated versus observed wind speeds at the VSt station. At $87 \mathrm{~m}$ above the ground, there were correlations generally larger than 0.75 during the night hours, and generally larger than 0.80 during the day. At $36 \mathrm{~m}$, the values were slightly smaller at nighttime and very similar during the day. Figure 7 shows the standard deviation of the error (estimated minus observed values) divided by the mean observed wind speed at each hour (RSTD). RSTD was approximately $25 \%$ for both elevations considered.

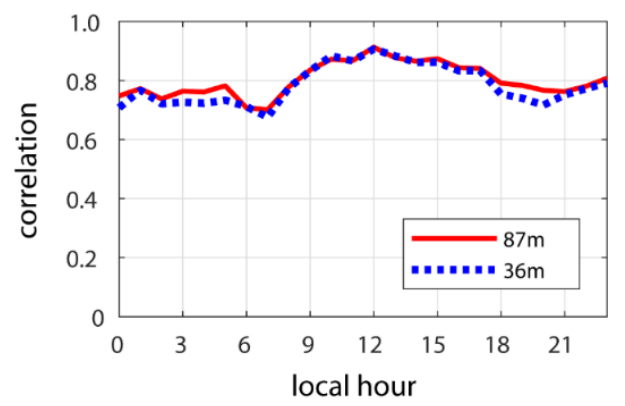

Figure 6. Pearson correlation of estimated wind versus observed wind as a function of the local hour at VSt. The red solid line shows the correlation at $87 \mathrm{~m}$ above the ground, and the blue dotted line shows at $36 \mathrm{~m}$. 


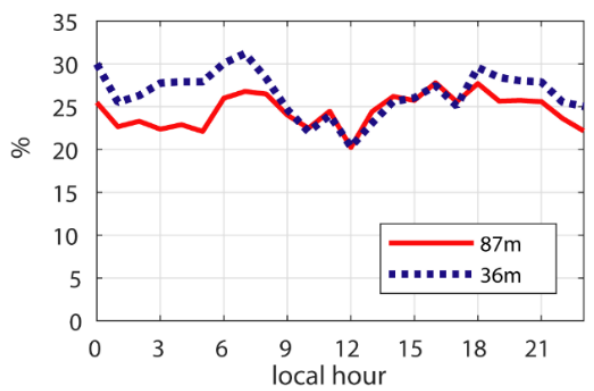

Figure 7. The relative standard deviation of wind estimate error as a function of the local hour at VSt. The red solid line shows the correlation at $87 \mathrm{~m}$ above the ground, and the blue dotted line shows at $36 \mathrm{~m}$.

Figure 8 shows scatter plots of estimated versus observed wind speeds at 7:00 and 12:00 and 87 and $36 \mathrm{~m}$ above the ground. These hours were chosen because they represent the periods of the day with the relatively worst and best adjustments, as assessed in Figures 6 and 7. Samples of assimilated values and the corresponding observed wind speed values, including those shown in Figure 8, made it possible to estimate probability distributions of the errors, such as empirical percentiles, from which confidence intervals for the wind speed estimates could be calculated.
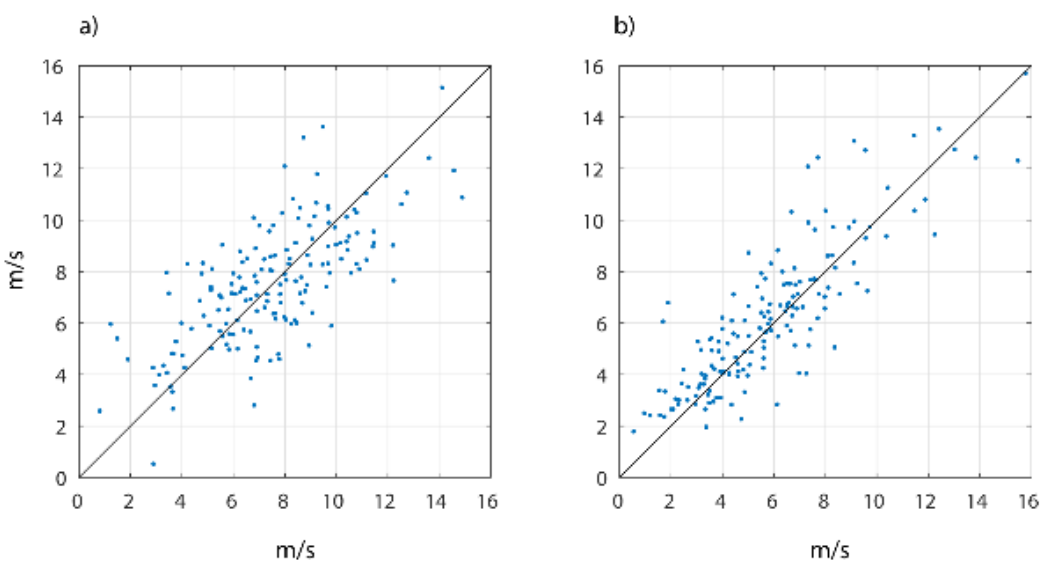

c)

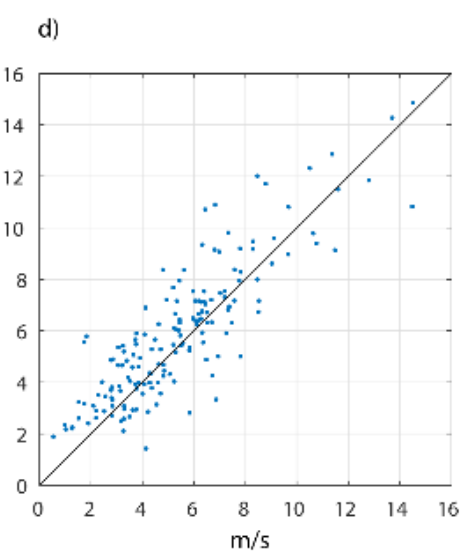

Figure 8. Estimated wind versus observed wind $100 \mathrm{~m}$ above the ground at VSt at (a) 7:00 and (b) 12:00. Estimated wind versus observed wind $30 \mathrm{~m}$ above ground at VSt at (c) 7:00 and (d) 12:00.

\section{Summary and Conclusions}

This work assessed the quality of wind speed estimates in Uruguay obtained with the WRF-DA system, which was used to assimilate wind speed measurements $100 \mathrm{~m}$ above the ground at two wind farms. The quality of the estimates was assessed with an anemometric station placed between the wind 
farms, that measured wind speed at 87 and $36 \mathrm{~m}$ above the ground. The information to be assimilated from field measurements was minimal, not only because it included only two stations but also because it lacked records of other atmospheric variables that are related to wind, such as atmospheric pressure. It was interesting to assess the extent to which these minimum field measurements could generate useful interpolations and evaluate the quality of the wind estimates at elevations both similar and different to those of the assimilated records. The measurement station used to validate the wind speed assessments was placed between those used for the assimilation process, so the conclusions of the assessment are applicable only to regions between the two main stations.

Wind speed estimates showed a low systematic error at the verification station, generally below $0.5 \mathrm{~m} / \mathrm{s}$ at both 87 and $36 \mathrm{~m}$ above the ground. A relative systematic error was generally less than $5 \%$ of the average speed. This result indicated that the data assimilation technique effectively combined information from field measurements and background conditions. The assimilated measurements did not include information from elevations as low as $36 \mathrm{~m}$. The background conditions did contain information from these low elevations, but with systematic errors of their own. The assimilation technique managed to propagate the gain from the observations at $100 \mathrm{~m}$ above the ground in the wind farms to other regions and to lower elevations. The covariance matrix of the background condition error was essential to the propagation of these observational gains.

As for the total error, the correlation values between observed and estimated wind speed and the standard deviation of the total error of each estimate, generally about $1 \mathrm{~m} / \mathrm{s}$ to $1.5 \mathrm{~m} / \mathrm{s}$, suggested that the obtained estimates could be of sufficient quality to be useful in various applications. Some examples of applications in which such estimates are valuable are the estimation of wind climatology within the range of the considered height levels, retrospective simulations of transport processes and dispersion of air pollutants, or real-time estimation of environmental conditions in which systems whose operation can be affected by the wind are being used. In any case, the effective use of pseudo-observations in a specific application requires the estimation of their confidence intervals, which are necessary both to assess whether the accuracy of pseudo-observations is acceptable for the application in question and to take into account the effects of the uncertainty of these data if they are used. The generation of databases of pseudo-retrospective observations, such as the one presented in this work, allows for the estimation of these confidence intervals.

For future studies, we are interested in quantifying the effects of including atmospheric pressure observations on the quality of the results. We are also interested in evaluating the effect of expanding the region in which observations are collected for the assimilation of data on the results of the hot start option.

Finally, we pointed out that the topography of the studied region is not completely flat but is relatively smooth. This can contribute to the quality of results obtained by assimilating a few observations in numerical simulations with relatively low resolution. In the case of regions with relatively complex topography, the numerical simulation may require finer spatial resolution to properly take into account the effects of topography on the wind field. The proper quantity and location of measurement stations should also be evaluated in each case.

Author Contributions: Conceptualization, G.C.B., S.O.; methodology, G.C.B., S.O.; software, G.C.B., S.O.; validation, G.C.B., S.O.; formal analysis, G.C.B., S.O.; investigation, G.C.B., S.O.; resources, G.C.B.; data curation, G.C.B. and S.O.; writing—original draft G.C.B.; visualization, G.C.B.; supervision, G.C.B.; project administration, G.C.B.; funding acquisition, G.C.B.

Funding: This research was funded by UTE and the Comisión Sectorial de Investigación Científica (CSIC) of the Universidad de la República, Uruguay, grant number CSIC-UTE-2017-33. The Agencia Nacional de Investigaciòn Científica, ANII, Uruguay, founded earlier stages of this work, grant FSE-2011-6562.

Acknowledgments: UTE provided the data to do this study. The reviewers of this work made valuable comments and indications that contributed to its improvement.

Conflicts of Interest: The authors declare no conflicts of interest. 


\section{Appendix A}

The setting of the WRF model used in this work is analogous to that of the work by Cazes Boezio and Ortelli [12] which evaluates short-term forecasts of wind power generated in Uruguay. The horizontal resolution was $30 \mathrm{~km}$ in the zonal and meridional direction. Figure 3 shows the grid points used to compute air temperature, pressure, density, and vertical velocity. The grid points used to compute the zonal and meridional velocities (not shown) were staggered one half of the horizontal resolution in the zonal and the meridional directions, respectively, according to the Arakawa C-grid arrange [1].

The model setting employed considered 54 layers in the vertical direction. The model vertical coordinate is $\eta[1]$, defined as

$$
\eta=\frac{p_{d}-p_{T}}{p_{S}-p_{T}}
$$

where $\mathbf{p}_{\mathbf{d}}$ is the hydrostatic component of dry air pressure at a particular atmosphere level, and $\mathbf{p}_{\mathbf{s}}$ and $\mathbf{p}_{\mathrm{T}}$ are the analogous pressures at the Earth's surface and the atmosphere conventional top, respectively. In this work, the atmosphere top was set to $50 \mathrm{hPa}$. Table A1 gives the values of $\mathrm{h}$ at each layer interface.

Table A1. $\eta$ values at the top of each layer of the vertical discretization.

\begin{tabular}{cccccc}
\hline $\begin{array}{c}\text { Layer } \\
\text { Number }\end{array}$ & $\begin{array}{c}\text { h Value at } \\
\text { Layer Top }\end{array}$ & $\begin{array}{c}\text { Layer } \\
\text { Number }\end{array}$ & $\begin{array}{c}\text { h Value at } \\
\text { Layer Top }\end{array}$ & $\begin{array}{c}\text { Layer } \\
\text { Number }\end{array}$ & $\begin{array}{c}\text { h Value at } \\
\text { Layer Top }\end{array}$ \\
\hline 1 & 0.9880 & 19 & 0.9240 & 37 & 0.7135 \\
\hline 2 & 0.9969 & 20 & 0.9165 & 38 & 0.6911 \\
\hline 3 & 0.9950 & 21 & 0.9088 & 29 & 0.6668 \\
\hline 4 & 0.9935 & 22 & 0.9008 & 40 & 0.6406 \\
\hline 5 & 0.9935 & 23 & 0.8925 & 41 & 0.6123 \\
\hline 6 & 09910 & 24 & 0.8840 & 42 & 0.5806 \\
\hline 7 & 0.9899 & 25 & 0.8752 & 43 & 0.5452 \\
\hline 8 & 0.9861 & 26 & 0.8661 & 44 & 0.5060 \\
\hline 9 & 0.9821 & 27 & 0.8567 & 45 & 0.4630 \\
\hline 10 & 0.9777 & 28 & 0.8471 & 46 & 0.4161 \\
\hline 11 & 0.9731 & 29 & 0.8371 & 47 & 0.3656 \\
\hline 12 & 0.9682 & 30 & 0.8261 & 48 & 0.3119 \\
\hline 13 & 0.9629 & 31 & 0.8141 & 49 & 0.2558 \\
\hline 14 & 0.9573 & 32 & 0.8008 & 50 & 0.1982 \\
\hline 15 & 0.9513 & 33 & 0.7863 & 51 & 0.1339 \\
\hline 16 & 0.9450 & 34 & 0.7704 & 52 & 0.0804 \\
\hline 17 & 0.9382 & 35 & 0.7531 & 53 & 0.0362 \\
\hline 18 & 0.9312 & 36 & 0.7341 & 54 & 0.0000 \\
\hline
\end{tabular}

The horizontal velocities and the air temperature were computed inside each layer, while the vertical velocity was computed at the layer interfaces, according to the Lorenz vertical grid arrangement [1].

The WRF model allowed us to choose several parameterizations of physical processes, especially for atmospheric boundary layer processes, surface layer processes, short and long wave radiative heat transfers, convective precipitation, clouds microphysics, and drag associated with gravity waves. Table A2 shows the parameterizations chosen in the current work and indicates references for them. 
Table A2. Parameterization of physical processes used.

\begin{tabular}{cc}
\hline Physical Process & Scheme Used \\
\hline Short Wave Radiation & Dudhia scheme [20] \\
\hline Long Wave Radiation & RRTM schene [21] \\
\hline Surface Layer & Revised MM5 surface layer scheme [22] \\
\hline Atmospheric Boundary Layer & Yonsei University scheme [23] \\
\hline Microphysics & Hong et al. scheme [24] \\
\hline Cumulus Precipitation & Simplified Arakawa Schubert scheme [25] \\
\hline Gravity Wave Drag & Kim Arakawa scheme [26] \\
\hline Land Processes & Noah land surface model [27]
\end{tabular}

\section{Appendix B}

Kalnay [3] showed the result of the optimization indicated in Equation (A1), that yields the 3D-Var analysis $\mathbf{x}_{\mathbf{a}}$ and is equivalent to the result of the optimal interpolation procedure,

$$
x_{a}-x_{b}=B(\nabla H)^{T} \cdot\left[\nabla H \cdot B \cdot(\nabla H)^{T}+R\right]^{-1} \cdot\left[y-(\nabla H)\left(x_{b}\right)\right]
$$

We chose a particular variable and a particular grid point that corresponds to the $k$ th element of $\mathbf{x}_{\mathbf{b}}$ or $\mathbf{x}_{\mathbf{a}}$, according to the conventional order of these vectors. We defined the synthetic observation $\mathbf{y}$ at the chosen grid point as the $k$ th value of $\mathbf{x}_{\mathbf{b}}$ plus a conventional increment $\Delta$,

$$
y=x_{b}(k)+\Delta
$$

Since the $\mathbf{\nabla H}$ operator produces analogous variables to those of the vector of observations $y$ from $\mathbf{x}_{\mathbf{b}}$, and the analogous to the synthetic observation $\mathbf{y}$ in the background condition is $\mathbf{x}_{\mathbf{b}}(\mathbf{k})$, the correspondent $\mathbf{\nabla H}$ is a vector with all its terms equal to 0 , except the $k$ th element, which is equal to 1 , so

$$
H\left(x_{b}\right)=x_{b}(k) \text {, and } y-H\left(x_{b}\right)=\Delta
$$

The matrix $\mathbf{R}$ of covariance of observation errors has a single element, which is the covariance of the synthetic observation $\mathbf{y}$. We chose a conventional value $\mathbf{s}^{2}$ for this covariance. Rizvi [17] showed that with these choices, Equation (A2) yields

$$
x_{a}-x_{b}=\frac{B_{k}}{b_{k k}+\sigma^{2}}
$$

where $\mathbf{B}_{\mathbf{k}}$ is the $\mathrm{k}$ column of $\mathbf{B}$. Equation A5 indicates that the $\mathbf{x}_{\mathbf{a}}-\mathbf{x}_{\mathbf{b}}$ difference is proportional to a vector that gives all the covariances of the error of $\mathbf{x}_{\mathbf{b}}(\mathbf{k})$ with the errors of all the other variables of $\mathbf{x}_{\mathbf{b}}$. Note that the $\mathbf{x}_{\mathbf{a}}-\mathbf{x}_{\mathbf{b}}$ difference is independent of the $\mathbf{x}_{\mathbf{b}}$ condition chosen. Plots of $\mathbf{x}_{\mathbf{a}}-\mathbf{x}_{\mathbf{b}}$ fields for $\mathbf{a}$ selected variable at a selected level of the numerical domain can help to understand the geographical structure of the error covariances of that variable at that level.

Here, we chose to increase in $1 \mathrm{~m} / \mathrm{s}$ the zonal ("test A") and the meridional ("test B") wind of a particular $\mathbf{x}_{\mathbf{b}}$ condition at the grid point and level closest to the location of the Vst station and the level of $87 \mathrm{~m}$ above ground. $\mathrm{s}$ was chosen as $1 \mathrm{~m} / \mathrm{s}$. Figure A1a shows the $\mathbf{x}_{\mathbf{a}}-\mathbf{x}_{\mathbf{b}}$ field for zonal velocity resulting from test $\mathrm{A}$, at the same model level of the selected grid point (level 7 from the ground). Figure A1b shows the $\mathbf{x}_{\mathbf{a}}-\mathbf{x}_{\mathbf{b}}$ field for the meridional velocity at the same level, for "test B". These results indicated that WF1 and WF2 were located in regions, where the zonal and meridional winds are well correlated with those of the Vst, and, therefore, wind estimates at this location benefit from 
observational gains obtained at WF1 and WF2. Besides, this type of analysis can be useful to define the density of a station network intended to cover a specific area.

Figure A2 shows the vertical profile of the $\mathbf{x}_{\mathbf{a}}-\mathbf{x}_{\mathbf{b}}$ zonal wind difference for test $A$, at the point of the horizontal grid in which the increase of zonal wind speed was prescribed. This profile shows the vertical structure of the covariances of zonal velocity background errors with the background error at the level chosen for the test. It was found that these covariances increased with the elevation up to $500 \mathrm{~m}$ above the ground, and then decreased to values that were close to 0 in the upper atmosphere (Figure A2a). Figure A2b shows a zoom of the profile shown in Figure A2a for the first $150 \mathrm{~m}$ above the ground, in order to focus on the levels of interest to this work. Although covariances were lower at lower elevations, their relatively large values indicated that observational gains obtained at elevations about $100 \mathrm{~m}$ could propagate quite directly to lower levels. The analogous vertical profiles from test $\mathrm{B}$ were found to be very similar to those from test $\mathrm{A}$, and are not shown here.

a)

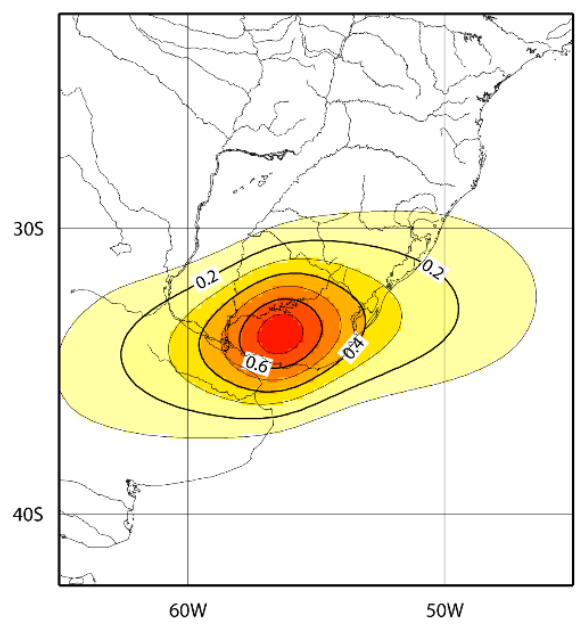

b)

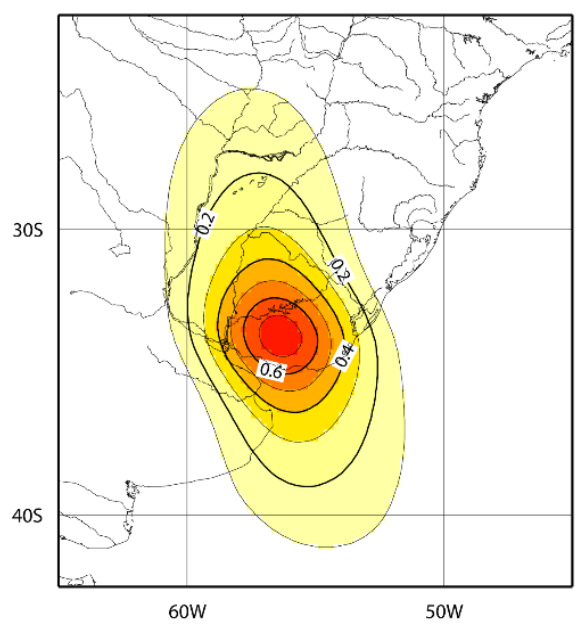

Figure A1. (a) $\mathbf{x}_{\mathbf{a}}-\mathbf{x}_{\mathbf{b}}$ zonal wind difference in test $\mathrm{A}$ at the 7 th layer of the model; $(\mathbf{b}) \mathbf{x}_{\mathbf{a}}-\mathbf{x}_{\mathbf{b}}$ meridional wind difference in test $\mathrm{B}$ at the same level. Contour interval, 0.1 (dimensionless).
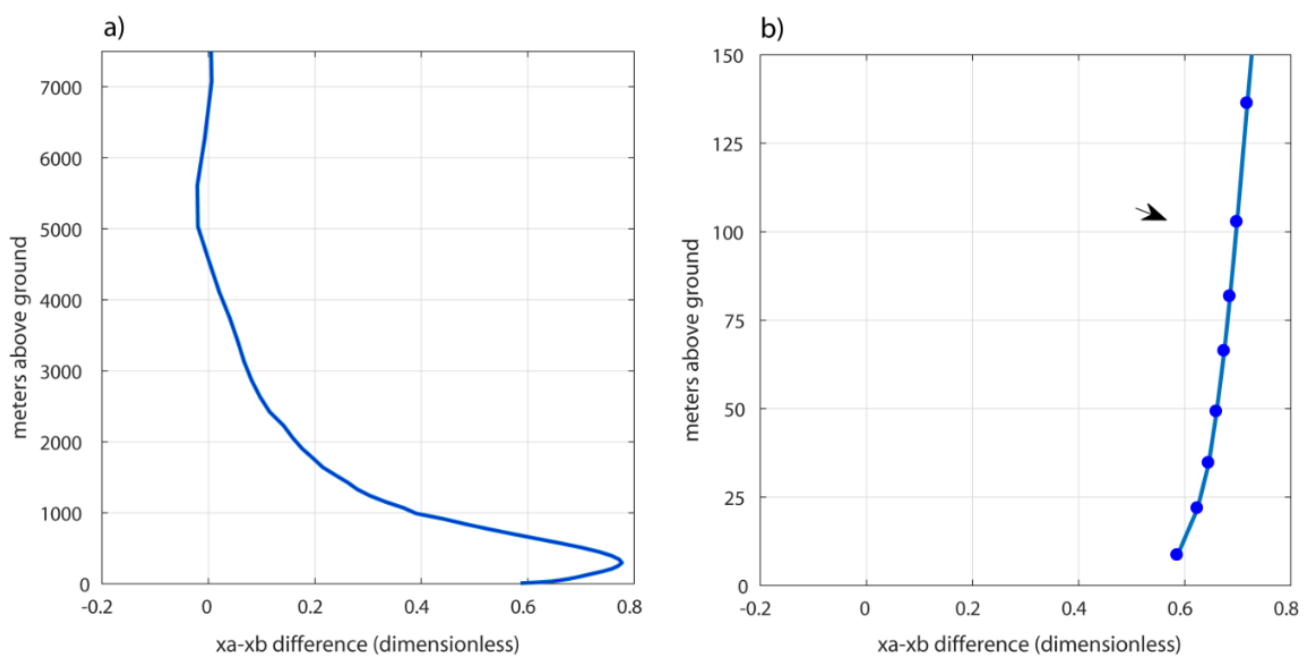

Figure A2. (a) Vertical profile of $\mathbf{x}_{\mathbf{a}}-\mathbf{x}_{\mathbf{b}}$ zonal wind differences in test $\mathrm{A}$ at the horizontal grid point closest to Vst location (for the first $8000 \mathrm{~m}$ above the ground). Abscissa, $\mathbf{x}_{\mathbf{a}}-\mathbf{x}_{\mathbf{b}}$ (dimensionless), ordinate, elevation above ground; (b) zoom of Figure A2, a vertical profile at the first $150 \mathrm{~m}$ above the ground. Dots indicate the model grid points, and the arrow, the grid point at which the perturbation is prescribed. 


\section{References}

1. Skamarock, W.C.; Klemp, J.B.; Dudhia, J.; Gill, D.O.; Barker, D.M.; Wang, W.; Powers, J.G. A Description of the Advanced Research WRF Version 3. NCAR Tech Note NCAR/TN-475+STR. Available online: http://citeseerx.ist.psu.edu/viewdoc/summary?doi=10.1.1.484.3656 (accessed on 25 October 2019).

2. Barker, D.; Huang, X.Y.; Liu, Z.; Auligné, T.; Zhang, X.; Rugg, S.; Ajjaji, R.; Bourgeois, A.; Bray, J.; Chen, Y.; et al. The Weather Research and Forecasting Model's Community Variational/Ensemble Data Assimilation System, WRFDA. Available online: https://journals.ametsoc.org/doi/pdf/10.1175/BAMS-D-11-00167.1 (accessed on 25 October 2019).

3. Kalnay, E. Atmospheric Modelling, Data Assimilation and Predictability; Cambridge University Press: Cambridge, UK, 2003; p. 345.

4. Barker, D.; Huang, X.Y.; Guo, Y.-R.; Xiao, Q.N. A three dimensional (3Dvar) data assimilation system for use with MM5. Implementation and Initial Results. Mon. Weather Rev. 2004, 132, 897-914. [CrossRef]

5. Huang, X.Y.; Xiao, Q.; Barker, D.M.; Zhang, X.; Michalakes, J.; Huang, W.; Henderson, T.; Bray, J.; Chen, Y.; $\mathrm{Ma}, \mathrm{Z}$. Four-dimensional variational data assimilation for WRF: Formulation and preliminary results. Mon. Weather Rev. 2009, 137, 299-314. [CrossRef]

6. Wang, X.; Barker, D.M.; Snyder, C.; Hamill, T.M. A hybrid ETKF-3DVAR data assimilation scheme for the WRF model. Part I: Observing system simulation experiment. Mon. Weather Rev. 2008, 136, 5116-5131. [CrossRef]

7. Wang, X.; Barker, D.M.; Snyder, C.; Hamill, T.M. A hybrid ETKF-3DVAR data assimilation scheme for the WRF model. Part II: Real observation experiments. Mon. Weather Rev. 2008, 136, 5132-5147. [CrossRef]

8. Harlim, J. Model Error in Data Assimilation. In Nonlinear and Stochastic Climate Dynamics; Franzke, C., O'Kane, T., Eds.; Cambridge University Press: Cambridge, UK, 2017; pp. 276-317. [CrossRef]

9. Rao, V.; Sandu, S. A-posteriori error estimates for inverse problems. Procedia Comput. Sci. J. 2018, 20, 1256-1265.

10. Orteli, S.; Boezio, G.C. Construction of Empirical Speed-Power Curves in Wind Farms Installed in Uruguay. Application to Real-Time Data Quality Control and Estimation of Potential Generation in Case of Restrictions. X Brazilian Micrometeorology Workshop. Available online: https://www.even3.com.br/anais/micrometeorologia2017/64488-construcao-de-curvasde-velocidade-potencia-empiricas-em-parques-eolicos-instalados-no-uruguai-aplicacao-ao-contr/ (accessed on 25 October 2019).

11. Cornalino, E.; Draper, M. Planning the Distribution of Wind Farms in Uruguay in Order to Optimize the Operability of Large Amounts of Wind Power. Available online: www.fing.edu.uy/cluster/eolica/publi/ Cornalino_Draper_EWEC2012_FINAL.pdf (accessed on 29 October 2019).

12. Cazes Boezio, G.; Orteli, S. Minimum-cost numerical prediction system for wind power in Uruguay, with an assessment of the diurnal and seasonal cycles of its quality. Sci. Nat. 2018, 40, 206-210.

13. Barker, D.; Huang, W.; Guo, Y.-R.; Bourgeois, A. A Three-Demiensional Variational (3DVAR) Data Assimilation System for Use with MM5 (No. NCAR/TN-453+STR). Available online: https:/opensky.ucar.edu/islandora/ object/technotes\%3A309 (accessed on 25 October 2019).

14. User's Guide for the Advanced Research WRF (ARW) Modeling System Version 3.9 WRF-ARW, Chapter 6. Available online: http://www2.mmm.ucar.edu/wrf/users/wpsv3.9/known-prob-3.9.html (accessed on 25 October 2019).

15. Parrish, D.F.; Derber, J.C. The National Meteorological Center's spectral statistical interpolation analysis system. Mon. Weather Rev. 1992, 120, 1747-1763. [CrossRef]

16. Descombes, G.; Auligné, T.; Vandenberghe, F.; Barker, D.; Barré, J. Generalized background error covariance matrix model (GEN_BE v2.0). Geosci. Model Dev. 2015, 8, 669-696. [CrossRef]

17. Rizvi, S. WRF-DA Background Error (Modeling and Estimation), WREF-DA Tutorial Presentation Slides, Chapter 4. University Corporation for Atmospheric Research, 2016. Available online: www2.mmm.ucar. edu/wrf/users/wrfda/Tutorials/2016_Aug/docs/WRFDA_BE.pdf (accessed on 29 October 2019).

18. Cataldo, J.; Universidad de la República, Montevideo, Uruguay. Personal communication, 2019.

19. Press, W.H.; Taukolsky, S.A.; Vettering, W.T.; Flannery, B.P. Numerical Recipes in Fortran 77: The Art of Scientific Computing; Cambridge University Press: Cambridge, UK, 1996; p. 1010. 
20. Dudhia, J. Numerical study of convection observed during the winter monsoon experiment using a mesoscale two-dimensional model. J. Atmos. Sci. 1989, 46, 307-310. [CrossRef]

21. Iacono, M.J.; Delamere, J.S.; Mlawer, E.J.; Shephard, M.W.; Clough, S.A.; Collins, W.D. Radiative forcing by long-lived greenhouse gases: Calculations with the AER radiative transfer models. J. Geophys. Res. 2008, 113, D13103. [CrossRef]

22. Jimenez, P.; Dudhia, J.; Gonzalez-Ruoco, J.F.; Navarro, J.; Montavez, J.P.; Garcia-Bustamente, F. A revised scheme for the WRF surface layer formulation. Mon. Weather Rev. 2012, 140, 898-918. [CrossRef]

23. Hong, S.-Y.; Noh, Y.; Dudhia, J. A new vertical diffusion package with an explicit treatment of entrainment processes. Mon. Weather Rev. 2006, 134, 2318-2341. [CrossRef]

24. Hong, S.Y.; Dudhia, J.; Chen, S.H. A Revised Approach to Ice Microphysical Processes for the Bulk Parameterization of Clouds and Precipitation. Mon. Weather Rev. 2004, 132, 103-120. [CrossRef]

25. Grell, G.A. Prognostic evaluation of assumptions used by cumulus parameterizations. Mon. Weather Rev. 1993, 121, 764-787. [CrossRef]

26. Kim, Y.J.; Arakawa, A. Improvement of Orographic Gravity Wave Parameterization Using a Mesoscale Gravity Wave Model. J. Atmos. Sci. 1995, 52, 1875-1902. [CrossRef]

27. Niu, G.-Y.; Yang, Z.L.; Mitchel, K.E.; Chen, F.; Ek, M.B.; Barlage, M.; Kumar, A.; Manning, K.; Niogi, D.; Rosero, E. The community Noah land surface model with multiparameterization options (Noah-MP): 1. Model description and evaluation with local-scale measurements. J. Geophys. Res. 2011, 116, D12. [CrossRef]

(C) 2019 by the authors. Licensee MDPI, Basel, Switzerland. This article is an open access article distributed under the terms and conditions of the Creative Commons Attribution (CC BY) license (http://creativecommons.org/licenses/by/4.0/). 